http://dx.doi.org/10.18778/8142-006-8.08

\title{
SPACE, SHAPE AND Movement IN Signing AND THE GENDERING OF VISUAL LANGUAGES
}

\author{
KATARZYNA WOJTANIK \\ Institute of English Studies, University of Lodz
}

According to statistics, in Poland about 900,000 people suffer from severe hearing impairments. In Europe, the statistics reach the number of 80 million. Globally, about $10-15 \%$ of the whole population, that is about 500 million people, experience hearing problems (Zatrudnij Gtuchych). Deaf and headof-hearing people use sign language to communicate. Many researchers have proved that sign languages are real, fully-fledged languages with complex grammatical rules which allow their users to communicate with precision. Despite being convinced that they deal with real languages, researchers argue whether and how signing differs from or is similar to spoken languages (Barberà 24). Comparing the two systems - spoken languages and signed languages ${ }^{1}$ Hickmann states that they subdivide into different subsystems. While spoken languages comprise four subsystems, i.e. lexical subsystem, grammatical subsystem, subsystem of "vocal dynamics," and somatic subsystem, sign languages consist of a few more, i.e. a subsystem of lexical forms, an "inflectional" subsystem, a subsystem of size-and-shape specifiers (or SASS's); a subsystem of "classifier expressions," a gestural subsystem, a subsystem of face, head, and torso representations, a subsystem of "bodily dynamics," and a somatic subsystem.

As argued by Barberà, modality should be understood as a way "the language is perceived and produced" (32). While spoken languages base mostly on audio-vocal modality, sometimes supported by visual-gestural modality, sign languages are integrated with visual-gestural, or visual-spatial modality, which constitutes the core of these languages. It means that such elements as space, movement and shape are crucial elements in these languages, i.e. these languages cannot exist beyond these components. All

\footnotetext{
${ }^{1}$ The author uses the term signed languages although it seems that the term sign languages would be better in this place. Signed languages are generally understood as artificial systems of communication based on the grammar of a spoken language and lexical signs of a sign language. In Poland teachers often use System Językowo-Migowy (Polish Signed Language, or manually-coded Polish).
} 
grammatical aspects of sign languages, i.e. phonology, morphology, syntax and lexis are expressed in space through shape and movement. It means that all the three elements are not spontaneous and accidental but their properties are particularly meaningful in communication. Referring to Klima and Bellugi, Barberà claims that space in signing does not constitute only a "field" in which communication process takes place, but it bears a significant linguistic meaning (25). The place of articulation (Barberà 26), which means that the location in which a particular sign appears, or is used, constitutes an important phonological category, as it is one of the minimal parameters which influence the meaning of the sign (Barberà 26). To illustrate this phenomenon let us analyse three signs from the Polish Sign Language (PJM): 1) SŁYSZACCY (HEARING PERSON), 2) CUKIEREK (CANDY), and 3) KOŚĆ (BONE). All three signs are produced with a curved index finger, on the right ear, on the right cheek, on the chin, respectively. The three signs constitute minimal pairs which are differentiated from one another by the place of the articulation alone (Tomaszewski, Rosik 113). Analysing sign language structure on the phonological level, Perniss in Space and Iconicity in German Sign Language (DGS) indicates four phonological parameters which allow one to create minimal pairs, i.e. handshape, place of articulation, movement, and hand orientation. All these categories are strongly related to space, which means that spatiality is a dominant criterion constituting the specificity of sign languages.

The aim of this paper is to present and discuss the three aspects mentioned above, i.e. space, movement and shape, and to show how they operate within sign languages. Space, shape, and movement are key elements of any sign language. Sign languages, as fully-fledged systems of communication, also contain linguistic variables which are typical for particular groups of signers, either regionally or socially. Signs, as words, may differ from a region to a region, or from the generation to the generation. In the final part of this paper, I will focus on sociolinguistic variation in sign languages, particularly in the context of gender differences in signing. Referring to the selected research, I will try to examine whether the three crucial building blocks of a sign language - space, shape, and movement are used differently by Deaf women and Deaf men.

Being a meaningful constituent of sign languages, a sign space is shaped in a very specific way. A sign space is not any space around the signer but it is limited to the frontal and the horizontal plane in front of the signer's torso (Barberà 25). The signs can be also located on the signer's body, which, thus, becomes a meaningful element of communication, called by researchers a non-manual articulator (Perniss, Space and Iconicity 219). Analysing the use of space, Perniss in Space and Iconicity in German Sign Language (DGS) 
mentions two ways in which the space can be used, i.e. the syntactic use of the sign space and the topographic use of the sign space. The syntactic use of the sign space means that the sign space loci are chosen arbitrarily and they do not carry any semantic meaning. Their importance is constrained to the syntactic aspect. In this sense, they become points of reference for other signs which, accordingly, can be meaningfully used, e.g. they allow to identify the agent and the object of a verb. Various morphosyntactic changes of signs can be performed within the sign space used syntactically, due to which a signer is able to introduce desirable changes of meaning and they can convey a specific message. For example, a signer can choose the direction of movement from locus 1 to locus 2 to communicate who is asking and who is being asked. To illustrate this aspect of the spatiality of a sign language, I will refer to Tomaszewski and Rosik's example of three Polish Sing Language utterances:
[A] BOY-R ${ }^{2}$
GIRL-L boy-LOOK AT-girl
[B] GIRL-L
BOY-R girl-LOOK AT-boy
[C] BOY-R
GIRL-L they-LOOK AT-each other. (116)

If one associates locus 1 with the sign "boy" and locus 2 with the sign "girl," depending on the order and the direction of signing (from locus 1 to locus 2, or from locus 2 to locus 1), they can obtain two different meanings:

[A] The boy is looking at the girl.

[B] The girl is looking at the boy. (Tomaszewski and Rosik 116)

If the signer uses two hands simultaneously, and s/he signs LOOK AT, moving both hands from the lateral positions towards the middle of the sign space, they can produce yet another utterance:

[C] A boy and a girl are looking at each other. (Tomaszewski and Rosik 116)

In the examples provided above, the locations in the sign space are used syntactically, which means that the locations have purely referential meaning. ${ }^{3}$ To illustrate the syntactic use of the sign space, Perniss in "Use of Sign Space" mentions Liddell's comparison of the sign space locations to terms used in a legal contract:

Liddell $(1990,304)$ likens the relationship of referential equality to the terminology of a legal contract. If Mr. Jones is identified as "the borrower" in

\footnotetext{
${ }^{2} \mathrm{R}$ stands for right hand, $\mathrm{L}$ stands for left hand.

${ }^{3}$ The term referential equality was used by Liddell (1990).
} 
a contract, then all subsequent mentions of "the borrower" within that contract refer to Mr. Jones, since the use of the phrase "the borrower" is referentially equivalent to the man called Mr. Jones. (414)

Trying to answer the question whether Polish Sign Language is a real language, Tomaszewski and Rosik call attention to a very interesting specificity of the spatiality of sign languages, i.e. spatial syntax ${ }^{4}$ of these languages. To illustrate their idea, they provide an example of a simple phrase: Mama poszła do sklepu (Mum went to the shop). The sentence can be signed in two ways:

[1] MOTHER-R

[2] MOTHER-R
GO TO-LSHOP-L

SHOP-L GO TO-L. (Tomaszewski and Rosik 118)

After assigning the sign MOTHER to location 1, a signer can, then, follow with the sign GO TO, and then sign SHOP in location 2 of the sign space. In the second option, a signer can start with the sign MOTHER in location 1, then, move on to the sign SHOP in location 2, and finally connect the two loci by an agreement verb (Barberà 27) GO TO. Regardless of the sequence of signs in the utterance, its meaning does not change. Thus, it can be further concluded that the spatial syntax likens sign languages to inflectional spoken languages, in which, due to inflectional endings, the sequence of words can be freely, or almost freely, chosen, and such an operation does not change the meaning of the utterance. Positioned in a specific location, the signs function as inflected words, the location being the spatial equivalent of spoken inflectional endings. In this sense, the location of a sign in the sign space corresponds to the inflection of a word, i.e. signs in particular locations in the sign space resemble inflected words with their inflectional endings. In this sense, Tomaszewski and Rosik are right talking about spatial inflection (fleksja przestrzenna) (118).

Contrary to the syntactic use of space, where the sign space loci are arbitrary, the sign space used topographically means that locations of the signs covey very specific meanings. The organisation of the sign space, i.e. location of signs in the sign space reflects spatial relations between real objects which the signs refer to (Perniss, "Use of Sign Space" 414). To discuss the sign space used topographically, Liddell uses the term location fixing, in which the location of a sign in the sign space corresponds to

4 In their article Tomaszewski and Rosik (2003) use the term fleksja przestrzenna (spatial inflection), but, since the phenomenon described in the article deals with the order, or the sequence, of signs in a signed utterance and their relation with, or influence on the meaning of the whole utterance, it seems that we should rather talk about skladnia przestrzenna (spatial syntax) in Polish Sign Language. 
location of the object it refers to in the real world. The correspondence between the organisation of the sign space and the organisation of space in the real world brings to mind the issue of iconicity of languages. Due to the visual-spatial modality, iconicity constitutes an inherent element of sign languages. As argued by Perniss in Space and Iconicity in German Sign Language (DGS), "the visual-spatial modality" carries "the potential for iconic representations" (3). She claims that three-dimensional space in which sign languages operate, naturally leads to iconic representations of a message, particularly, if the message concerns shape, location, motion, and action (Perniss, Space and Iconicity 3). The topographic use of the sign space shows to what extent iconicity is present in sign languages, i.e. that it can be equally traced on the discourse level. The topographic use of the sign space is often related to the use of classifier predicates, which will be discussed in the second section of the paper.

A particular locus in the sign space can be used both syntactically and topographically at the same time, and these two dimensions do not necessarily stand in opposition to one another. Let us look at the example that Perniss provides in "Use of Sign Space:"

A signer could use a classifier predicate to establish a referent, e.g. a colleague, at a certain (topographic) location in sign space, e.g. seated at her desk. Subsequently, the signer could direct a verb sign, e.g. ask, to the same location, specifying the colleague as the grammatical object of the predicate (see Liddell $(1990,318)$ for a similar example). In this example, the location associated with the colleague is functioning syntactically (or referentially) and topographically at the same time. (416)

Other researchers like Liddell and van Hoek go even further in their conclusions and claim that the two ways in which the sign space is used, i.e. syntactic and topographic one, are so closely integrated that one cannot really distinguish between them. The use of a particular locus is never purely syntactic or purely topographic. Referring to Fauconnier's theory of mental spaces, Van Hoek introduces the term of conceptual location, which means that every location is related to a certain context which deprives the location its abstractness, or arbitrariness (Perniss, "Use of Sign Space" 416).

The sign space, which is a precisely defined area in front of the signer's body where signed utterances are produced, can be structured in many ways, depending on the signer's needs and aims. Referring to Engberg-Pedersen's research, Perniss in "Use of Sign Space" provides three factors which make the signer decide upon the organisation, or the shape, of the sign space, i.e. semantic, pragmatic, and discourse cohesion (417). She then concludes that arbitrariness in choosing a locus, or loci, in the sign space happens extremely 
rarely. After Engberg-Pedersen's, Perniss discusses various conventions of structuring the sign space. When a signer organises the sign space to reflect the real world, or the real event, s/he is said to act within the iconic convention. The convention of semantic affinity is used when a signer produces an utterance in which referents stay in semantic relation to each other. In such a situation, the two signs are produced at one locus in the sign space. The convention of semantic affinity shares some features with the convention of canonical location, in which a referent is assigned to a location which is naturally associated with it. Perniss provides an example of a person who lives in a certain city ("Use of Sign Space" 417). A sign referring to the person will be produced at the same place as the sign signifying the city, even if the person is out of the city when the utterance is taking place.

A convention applied by a signer can also depict their attitude towards the topic of the conversation, or people spoken about. For example, signers can choose locations closer to their body to sign about something they like, or, if they want to express their dislike, they can locate referents further from their body. Perniss provides an example of two films discussed by a signer ("Use of Sign Space" 418). Producing an utterance about a film that the person liked, they sign closer to their body, while they choose a location further from their body to express their dislike. The convention of comparison allows signers to compare two phenomena by locating them on the right and on the left in the sign space, thus giving them equal but juxtaposing position. Finally, Perniss discusses the authority convention which allows signers to present superiority-inferiority relations by assigning the more important referent a higher location in the sign space ("Use of Sign Space" 418).

Furthermore, referring to Winston and Mather and Winston research findings, Perniss discusses how discourse cohesion is obtained through the use of spatial mapping ("Use of Sign Space" 418). This way of structuring the sign space allows signers to introduce different topics of conversation by assigning them different locations in the sign space. The visual representation of the discourse structure which is, thus, achieved can refer to both physical, existing entities, and to abstract concepts. To illustrate this structuring tool, Perniss in "Use of Sign Space" provides Mather and Winston's example of spatial mapping in American Sign Language (ASL) narrative:

[T] he narrator creates two main discourse spaces in sign space, one for inside a house and one for outside it. These main spaces are further subdivided to elaborate subtopics related to either of the main spaces, e.g. to describe events that take place inside or outside the house, respectively. (418)

The way signers structure the sign space depends on many factors. Some of them have been earlier discussed in this paper and have been classified into 
different structuring conventions, e.g. iconic convention, convention of semantic affinity, convention of canonical location, convention of comparison, authority convention. Yet, the space shape in a signed utterance is related not only to the convention applied, ${ }^{5}$ but also to the perspective the signer takes. We can talk about two perspectives a signer can have while signing. They can either be a part of the utterance, which means that their body becomes a referent located in locus 1 (while other referents are located in loci 2,3 etc.), or they can present the event from outside it. The two perspectives are referred to as the observer perspective and the character perspective, respectively. Depending on the perspective, the sign space changes its character. When the signer's body becomes a referent in the sign space, i.e. when the character perspective is applied, the sign space changes its shape, i.e. it is expanded from the area in front of the signer's body to the area around them. Such a space is called surrogate space. When the signer takes the observer perspective, the sign space in front of them is called token space (Perniss, "Use of Sign Space" 419).

A characteristic feature of the sign space is its capability of incorporating multiple meaningful units, i.e. referents, at the same time. Such a phenomenon is possible due to the fact that sign languages are based on visual-spatial modality which allows signers to use two or more independent articulators where each articulator provides to the utterance a separate meaningful unit. Articulators involved in the construction of simultaneous representations are not necessarily hands. They can also include eyes, torso, face (Perniss 424). Simultaneous constructions fall into different categories depending on their structure or function. From the structural, or formal, point of view, simultaneous constructions can be divided into two categories:

a) truly simultaneous constructions in which "two one-handed signs are produced at the same time"

b) sequential "but in overlap (i.e. one sign is produced first and holds during the production of one or more other signs)." (Perniss, Space and Iconicity 40)

Functionally, simultaneous constructions can be classified into two categories:

a) depicting spatial/temporal organization

b) depicting discourse organization. (Perniss, Space and Iconicity 40)

${ }^{5}$ The choice of a structuring convention is an unconscious act, and is secondary to the act of communication itself, i.e. repetitiveness of certain structuring patterns in particular circumstances allows to call the pattern a convention, not the other way round. 
The author enumerates six functions of simultaneous constructions. Let us quote Perniss' categories:

1) referent representation on both hands to express spatial information (in the depiction of the spatial relationship between two referents)

2) referent representation on both hands to express the temporal and spatial simultaneity of events (in the depiction of action or interaction between referents)

3) the expression of temporal simultaneity of events or states (aspectual information)

4) the hold of a topic on one hand while the other hand signs related information (topic - comment structure)

5) the hold of an enumeration morpheme on one hand while the other hand signs one or more related signs

6) the hold of an index sign on one hand while the other hand signs one or more related signs. (Space and Iconicity 40)

To facilitate the reception of a message conveyed through a simultaneous construction, a signer chooses one articulator to be the dominant one. The signs produced on the non-dominant hand are called by Liddell buoys. They are kept unchanged throughout the whole action of the dominant hand. Liddell categorises the buoys signs into four classes: 1) list buoys 2) pointer buoys, 3) theme buoys, 4) fragment buoys (Perniss, Space and Iconicity 42). A detailed analysis of these signs is not the subject of this paper but it seems worthwhile focusing on the third category and compare it to the issue of thematisation discussed by Tomaszewski and Rosik (120-121). As argued by Perniss (Perniss, Space and Iconicity 42), Liddell's characterizes a theme buoy "a raised, vertical index finger on the non-dominant hand." Such a sign introduces an important theme to the discussion. In Tomaszewski and Rosik's analysis, in Polish Sign Language (PJM), the introduction of a new topic takes place through the application of non-manual components, such as raising eyebrows, narrowing eyes, or raising one's head. These components inform the addressee of the message that a new theme has been introduced.

Undoubtedly, in the analysis of sign languages which operate within visual-spatial modality, the issue of shape can be approached from very different perspectives. As discussed above, we can talk about the shape of space, depending on the purpose it is used for. For example, it can take the shape of a real space in which an action takes place, thus, becoming a meaningful component of a discourse. Such a space is present in the topographic use of space. On the other hand, space can constitute only a frame in which signs are produced. Such space can take any shape, so it can be further concluded (if the conclusion is not far-fetched) that, paradoxically, such a space is shapeless. It appears when the sign space is used syntactically. 
The analysis of shape, or shapes, in a discussion concerning sign languages concentrates mostly on the analysis of handshapes used by signers to produce their utterances. It seems that the two elements - space and shape - are inseparable and interdependent, i.e. it would be impossible to describe, or even notice, space (the sign space) if it were not for shapes, i.e. signs which appear within it. Such a space would be absolutely useless, or meaningless, like grammatical rules without lexical items. Likewise, shapes cannot exist outside space, similarly to words which cannot exist out of time.

Despite using different modalities, sign languages and spoken languages share a common feature which lies at a very deep level of their linguistic construction, i.e. both sign and spoken languages use abstract components to build meaningful signs and words, respectively. Every sign language uses a different set of handshapes to produce signs, but, as Perniss in Space and Iconicity in German Sign Language (DGS) claims there is a group of handshapes which reappear in different sign languages. It seems that comfort as well as linguistic economy would influence the frequency of usage of certain handshapes in signs. Basic handshapes used in signs can be traced in the alphabets of different sign languages. The alphabets differ from sign language to sign language, some being one-handed, like Polish Sign Language alphabet, or American Sign Language alphabet other - twohanded, like British Sign Language alphabet. The names of handshapes are often related to letters they signify. The knowledge of the handshape names of a particular language is very useful, especially when someone wants to describe such a language, e.g. in sign language course books.

Although linguists are generally convinced that the lexicons of languages contain mostly arbitrary signs, sign languages seem to break this rule. Due to their visual-spatial modality, the iconicity in these languages seems to appear in a natural way, both on the lexical and morphosyntactic levels (Perniss, Space and Iconicity 22). In her analysis, Perniss presents a very interesting concept of iconicity being constrained by some prototypical images that are preserved in languages (Space and Iconicity 6). Perniss seems to claim that within languages there operate some prototypical, culture-specific conventions which make the users of the language choose certain features of an object, while omitting other characteristics, to create an iconic representation of the object. Users of different languages choose a different set of features to make their linguistic signs, i.e. they apply different conventions in the process of language creation. In this way, iconic signs become conventionalised within a language and they cannot be easily recognised by a user of a different sign language or by non-signers. Once the convention is revealed to a foreign user of a particular sign language, they can easily indicate the similarity between the sign and the real object it 
signifies. Perniss (Space and Iconicity 6) uses an example of a sign EAGLE in German Sign Language (DGS) and in Ugandan Sign Language (USL). In both languages, the signs are iconic, though different characteristics of the object, in this case an eagle, have been chosen to create the sign. In German Sign Language (DGS), the sign is based on a hooked nose of the bird, while in Ugandan Sign Language (USL) the sign refers to the bird's claws. If we take the same example of the sign EAGLE in Polish Sign Language (PJM) and in American Sign Language (ASL), it will turn out that in this case the concept of conventionalization of iconic signs is also applicable. The conventionalised iconic signs are shown in Figure 1 below.

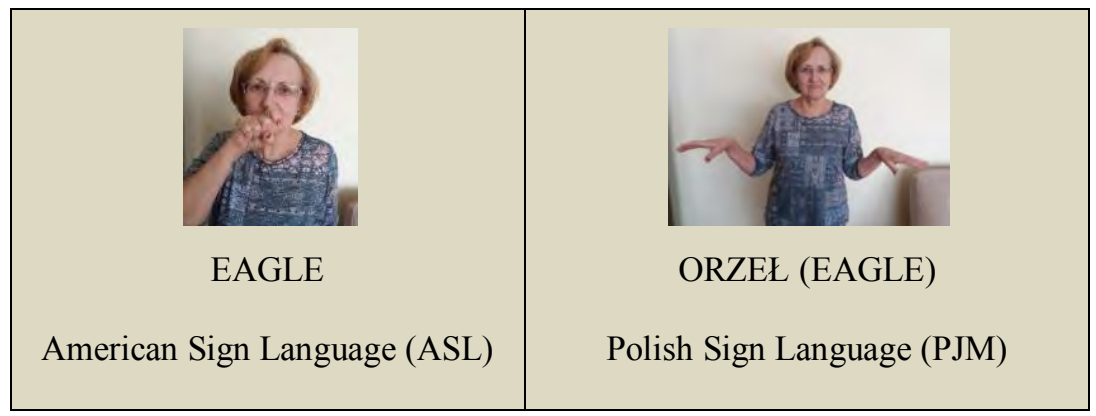

Figure 1. Conventionalized iconic signs in American Sign Language (ASL) and Polish Sign Language (PJM)

The second factor which influences the shape of a sign in a particular sign language refers to, what Perniss calls, "the phonological means" (Space and Iconicity 6) which are applied to transfer the features from the object to the sign, i.e. to map the object form on the sign form. In this case, Perniss uses the sign TREE in German Sign Language (DGS), Chinese Sign Language (CSL) and Danish Sign Language (DSL). The three signs are conventionalised iconic signs, in which not only different characteristic features are chosen to create the sign, but also a different handshape, hand orientation, or other minimal parameters are applied to make the sign. Let us look at the sign HOUSE in American Sign Language (ASL) and DOM (HOUSE) in Polish Sign Language (PJM), which are shown in Figure 2.

\footnotetext{
${ }^{6}$ All the pictures used in this paper have been taken by the author.
} 


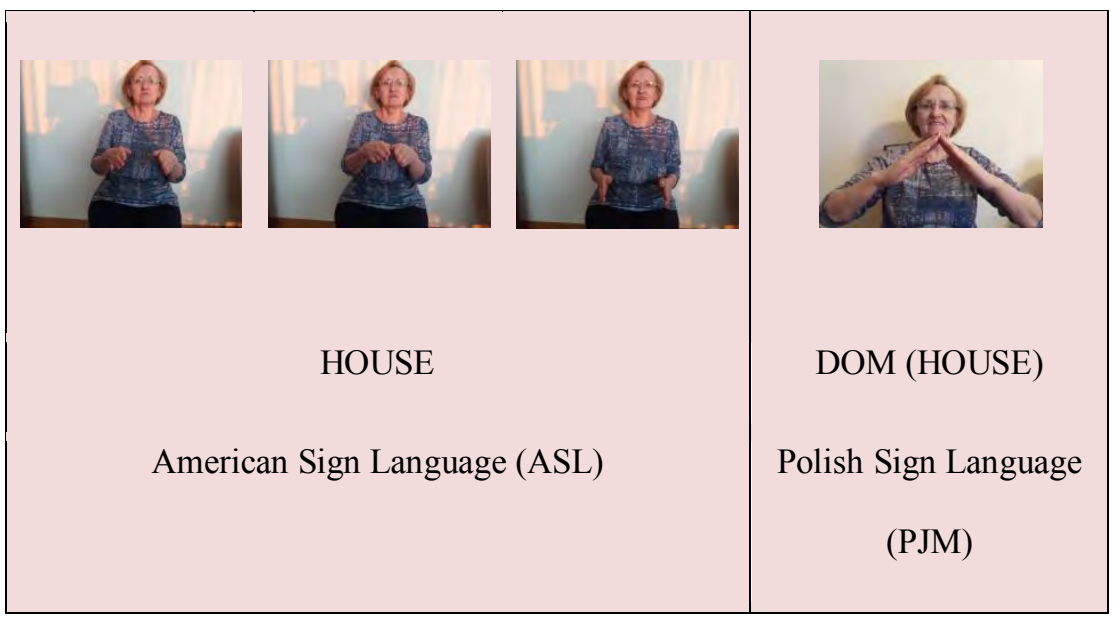

Figure 2. Phonological differences within conventionalized iconic signs in American Sign Language and Polish Sign Language

In the example presented in Figure 2, the sign HOUSE in American Sign Language (ASL) and in Polish Sign Language (PJM) is conventionalised in a similar way, i.e. similar characteristics of the object are chosen to create the sign. In both cases, the element of the roof constitutes the constructing element of the sign, though the sign in American Sign Language is more complex, as it also contains a second component which refers to the walls of the house. But, the feature which additionally differentiates the two signs is the phonological parameter, i.e. the hand orientation. In both languages, the B-handshape is applied - in the American sign, fingers are facing forward, while in the Polish sign, they are directed upward.

Let us now refer to some typical classifier predicates that function within Polish Sign Language (PJM). Figure 3 shows four typical classifier predicates used in Polish Sign Language (PJM). 


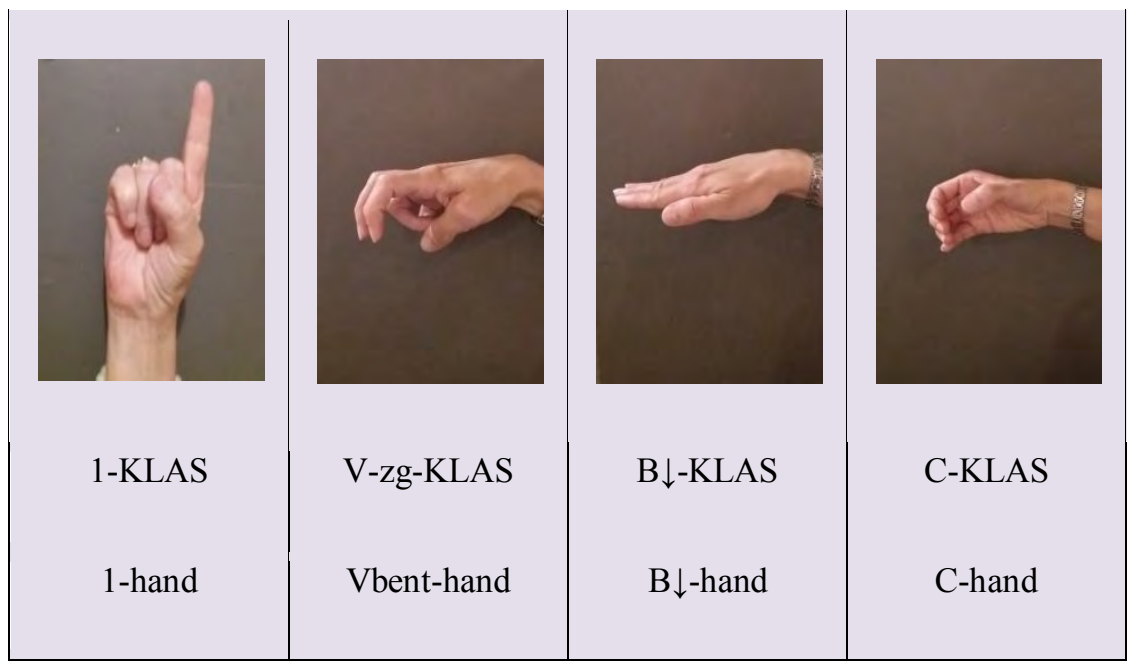

Figure 3. Examples of classifier predicates in PJM

The classifier predicates presented in Figure 3 are only a few examples of this class of signs used in Polish Sign Language (PJM). The 1-KLAS classifier predicate, which is the index finger directed upward, other fingers and the thumb making a fist, is used to signify persons, e.g. mother, father, teacher, friend. The V-zg-KLAS handshape, which is letter V bent and kept palm downward, is used to refer to certain animals, e.g. cat, dog, hare, wolf. The $\mathrm{B} \downarrow$-KLAS classifier predicate is a letter B kept flat, palm downward and it is used to signify vehicles, such as, for example, a car. The last example in Figure 3 is the C-KLAS classifier predicate, which is a $\mathrm{C}$ letter handshape, and it is used to refer to such objects as trees, but also glasses, bottles, monuments, or buildings (Tomaszewski, Rosik 123-129). The moment classifier predicates are used in an utterance is strictly specified, i.e. signs in an utterance appear in a certain order which is governed by the rule saying that classifier predicates have to refer to objects which have been specified earlier. It means that the use of a classifier predicate is always preceded by the use of a lexical sign (Tomaszewski, Rosik 124).

Another feature which is typical of sign languages, and which derives from the visual-spatial modality of these languages, is movement. It constitutes an inherent element of the language, which is clearly visible in the fact that it constitutes one of the four minimal parameters which take part in the construction of the meaning of signs. As mentioned in the previous section, one or both hands can be involved in movement when a sign is 
produced. It thus can be stated that in signs where one or two hands are active, movement constitutes an inherent element of the sign, i.e. it is a constructive element of the sign. In this sense, being an element of the sign structure, movement gains physicality. Tomaszewski and Rosik notice a different feature of movement, i.e. the fact that classifier predicates are never constructed by the use of a handshape alone, but that movement is always involved in the production of such signs (124). It reflects the action performed by the agent, which is presented through a classifier predicate. In this sense, movement contextualises the sign, forcing it to exist in a certain way, not just to exist. Movement used in relation to a classifier predicates reveals its vivifying nature.

Movement can also play a qualitative role in an utterance. In this sense, movement acquires the properties of an adjective or an adverb. This feature of movement is very often used in simultaneous constructions. A signer does not have to use a separate sign to depict a certain quality of movement, such as, for example in a sentence: "Mother dashed to catch the bus." The way mother moved is expressed by the tempo of the movement. Apart from the movement, the quality of mother's action is also visible in the signer's body and face, the non-manual articulators which also take part in meaning production.

Before we move on to the final section and examine the issue of sociolinguistic variations in the context of gender differences in sign languages, let us first investigate whether sign language users are aware of gender issues and, if so, how this awareness is expressed in the language. To answer these questions let us refer to Kelly's research of five Deaf ASL teachers. All of women had hearing or hard-of-hearing parents who did not sign. The women struggled to communicate orally at home and, as it might be expected, the quality of the communication was rather poor, to say the least. They learned ASL as their primary language in residential schools for deaf children. Their school time coincided with important changes in social and cultural life in the United States, which led to the recognition of equal rights for women as well as for racial and cultural minorities. The socio-cultural background of the participants constituted a significant element of the research as Kelly tried to examine whether gender issues were present in ASL and, if so, how they were expressed. In the first part of her research Kelly wanted to know how her informants signed gender and whether such a sign existed in their language. All of the women signed the compounded form MAN WOMAN. They offered finger spelled G-E-N-D-E-R as an alternative, but none of them proposed the compounded form of WOMAN MAN. Here is how the Kelly concludes this part of her study: 
I noticed that each woman offered MAN WOMAN to define gender, but they never transposed the order to WOMAN MAN. Thus [...] I inquired whether the sign order was influenced by an internalized stereotyped social notion that men are superior to women, or if the ASL production was a physical linguistic constraint. Upon being asked the question, [...] some reported that societal views about gender may have influenced how they sign. I then finger spelled P-A-R-E-N-T and asked how they signed that concept. Parent is often signed as MOTHER FATHER, with the female noun at the head of the compound, and it is rarely signed in reverse. This changed the informants' minds, and they cited location or comfort level as factors in signing MAN WOMAN rather than WOMAN MAN. [...] [A]fter discussing and experimenting with the form, [they] finally decided that location and physical comfort, not sociolinguistic influence, is the overriding factor in the sign sequence. (230-233)

As showed in Kelly's study, the internal construction of signs is often motivated by the comfort of using the language rather than any sociolinguistic factors; even signs for such terms as gender or parent, so important for the gender discourse, lack the sociolinguistic motivation in their internal construction. Here is how the researcher summarises the whole study:

[I]nformants in this study identified themselves as Deaf more than as women and not even as Deaf women. Their lives revolved around experiences of being Deaf, such as facing communication barriers in various social contexts. As teachers of ASL and Deaf culture, their Deaf identity/ies are much more salient than their gender identity.[...] Toward the end of this study, each participant confessed that she rarely considered gender issues and roles within her own life and the Deaf community. (Kelly 238-239)

Analysing the issue of sociolinguistic variation in American Sign Language Lucas, Bayley, and Valli conclude that:

[B]ecause natural sign languages are full-fledged autonomous linguistic systems shared by communities of users, the sociolinguistics of sign languages can be described in ways that parallel the description of spoken languages. It follows that sign languages must exhibit sociolinguistic variation similar to that seen in spoken languages. (Sociolinguistic Variation 4-5)

On the whole, numerous researchers have investigated the issue of sociolinguistic variation in ASL, but the study has been too limited to provide a definite answer to the question of how sociolinguistic variation operates within the sign language:

ASL users are also aware of sociolinguistic variation in ASL. However, many aspects of that variation have yet to be explored. In terms of linguistic 
structure, most of the studies to date focus on lexical variation, with some studies of phonological variation, and very few of morphological or syntactic variation. In terms of social factors, the major focus has been on regional variation, with some attention paid to ethnicity, age, gender, and factors that may play a particular role in the deaf community, such as audiological status of parents, age at which ASL was acquired, and educational background (e.g., residential schooling as opposed to mainstreaming). (Lucas, Barley, and Valli, Sociolinguistic Variation 5-6)

Referring to the concept of gender as a factor contributing to the creation of sociolinguistic variation in ASL, Lucas, Bayley, and Valli ask important questions (What's Your Sign For PIZZA):

Is there a solidarity in language use between men and women in a language minority group because of oppression from the outside and shared experiences rooted in being deaf? Or are usage differences as pronounced as in other communities? (160)

Many researchers investigating the issue of sign languages structure unanimously state that the sign languages function similarly to spoken languages, and, as fully-developed systems of communication, contain sociolinguistic variation. Similarly to spoken languages, gender is one of the key social factors which motivate the existence of sociolinguistic variation in sign languages. It is presumed that Deaf men and Deaf women use signing space, shape, and movement differently, which can be compared to the way hearing men and women use spoken languages. Lucas, Barley, and Valli (Sociolinguistic Variation 4) provide an example of different pronunciation of -ing ending by men and women, where men tend to pronounce it $/ \mathrm{n} /$, whereas women pronounce it $/ \mathrm{y} /$. It should be assumed that similar examples could be found in the phonology, morphology, syntax, and lexis of sign languages. However, gender-motivated sociolinguistic variation in sign languages has not been investigated yet. It seems that Deaf users of sign languages are more concerned with their Deaf identity and the struggle to exist as a social minority within the hearing world, rather than with the issue of gender differences. The example of the five Deaf ASL teachers shows that sign languages, and consequently Deaf culture, are probably not as gender sensitive as spoken languages and the culture of hearing people. A thorough study in this field is needed to deepen our understanding of how the gender factor (or the gender variable) influences the construction of sign utterances, as well as how sign languages operate within Deaf communities.

Due to their visual-spatial modality, sign languages constitute a unique class of languages. The three basic elements of all sign languages, i.e. space, shape, and movement make it possible to create utterances in a way which is 
inaccessible to spoken languages. A simultaneous construction is a perfect example here. The aim of this paper was to characterise the three crucial constituents of every sign language, and to show how sign languages' users utilise them to produce meaningful messages.

\section{Works Cited}

Barberà, Gemma. The Meaning of Space in Catalan Sign Language (LSC). Reference, specificity, and structure in signed discourse. Doctoral dissertation. Universitat Pompeu Fabra, 2012.

Brentari, Diane. Sign Languages. Cambridge University Press, 2010.

"Broszura informacyjna. Krajowa kampania informacyjno-promocyjna wspierająca osoby głuche i niedosłyszące w powrocie na rynek pracy i jako wartościowych pracowników." http://resgest.pl/wp-content/uploads/ 2016/01/zatrudnij_gluchych_broszura.pdf

De Saussure, Ferdinand. Course in General Linguistics. Philosophical Library, 1959.

Engberg-Pedersen, Elisabeth. Space in Danish Sign Language. The Semantics and Morphosyntax of the Use of Space in a Visual Language. SignumVerlag, 1993.

Fauconnier, Gilles. Mental Spaces. MIT Press, 1985.

Hickmann, Maya, and Stéphane Robert, editors. Space in Languages. Linguistic Systems and Cognitive Categories. Benjamins, 2006.

Van Hoek, Karen. "Conceptual Locations for Reference in American Sign Language." Spaces, Worlds, and Grammar, edited by Gilles Fauconnier, and Eve Sweetser, University of Chicago Press, 1996, pp. 334-350.

Kelly, Arlene Blumenthal. "How Deaf Women Produce Gendered Signs."

Women and Deafness Double Vision, edited by Brenda Jo Brueggemann, and Susan Burch, Gallaudet University Press, 2006, pp. 226-241.

Klima, Edward, and Ursula Bellugi. The Signs of Language. Harvard University Press, 1979.

Liddell, Scott. "Four Functions of a Locus: Reexamining the Structure of Space in ASL." Sign Language Research: Theoretical Issues, edited by Ceil Lucas, Gallaudet University Press, 1990, pp. 176-198.

Liddell, Scott K. Grammar, Gesture, and Meaning in American Sign Language. Cambridge University Press, 2003.

Liddell, Scott K. "Real, Surrogate and Token Space: Grammatical Consequences in ASL." Language, Gesture, and Space, edited by Karen Emmorey, and Judy. S. Reilly, Lawrence Erlbaum, 1995, pp. 19-41. 
Lucas, Ceil, Bayley, Robert, and Clayton Valli. Sociolinguistic Variation in American Sign Language. Gallaudet University Press, 2001.

---. What's Your Sign for PIZZA? An Introduction to Variation in American Sign Language. Gallaudet University Press, 2003.

Perniss, Pamela. Space and Iconicity in German Sign Language (DGS). Doctoral dissertation. Radboud University, 2007.

---. "Use of Sign Space." Sign Language: an International Handbook, edited by Roland Pfau, Markus Steinbach, and Bencie Woll, Mouton de Gruyter, 2012, pp. 412-431.

Pierce, Charles Sanders. Semiotic and Significs: The Correspondence between Charles S. Peirce and Victoria Lady Welby, edited by Charles Hardwick, Indiana University Press, 1977.

Poizner, Howard, Klima, Edward S., and Ursula Bellugi. What the Hands Reveal About the Brain. MIT Press, 1987.

Sandler, Wendy, and Diane Lillo-Martin. Sign Language and Linguistic Universals. Cambridge University Press, 2006.

Stokoe, William. Sign Language Structure. An Outline of the Visual Communication Systems of the American Deaf. Linstok Press, 1960.

Suppalla, Ted. "The Classifier System in American Sign Language." Typological Studies in Language: Noun Classes and Categorization, edited by Colette Craig, John Benjamins Publishing Company, 1986, pp. 181-214.

Szczepankowski, Bogdan. Niestyszacy, głusi, głuchoniemi: wyrównywanie szans. WSiP, 1999.

Tomaszewski, Piotr, and Paweł Rosik. "Czy Polski Język Migowy jest prawdziwym językiem?” Studia nad kompetencja językowa i komunikacja niestyszacych, edited by Marek Świdziński, and Tadeusz Gałkowski, Warszawa, 2003, pp. 109-143. 